\title{
Difficulty with right-left discrimination: A clinical problem?
}

\author{
Gerard Gormley MD, Ryan Brydges PhD
}

Competing interests: None declared.

This article has been peer reviewed.

Correspondence to: Gerard Gormley, g.gormley@qub.ac.uk

CMAJ 2016. DOI:10.1503 /cmaj.150577
I $\mathrm{n}$ our personal and professional lives, we make right-left decisions on a daily basis. For many, right-left discrimination is second nature, but for a substantial proportion of our population, distinguishing right from left is difficult. ${ }^{1,2}$ In a cohort of nearly 800 adults, about $9 \%$ of men and $17 \%$ of women selfreported difficulty in distinguishing right from left. ${ }^{3}$ Further, in a cohort of 290 medical students, more than $50 \%$ scored less than $77 \%$ on an objective right-left psychometric discrimination test. ${ }^{2}$ Right-left discrimination is a complex neuropsychologic process that calls upon several higher functions, including visuospatial processing, memory, language and integration of sensory information, ${ }^{1}$ and cerebral hemispherical asymmetry appears to be a contributing factor. ${ }^{4}$ Apart from minor inconveniences, such as a delay in arrival time from taking a wrong direction in a car journey, the impact of laterality errors is often negligible. In industries like aviation and health care, however, laterality errors have the potential to lead to devastating consequences. Guidance now exists for health care professionals on how to prevent wrong-side surgical operations, ${ }^{5}$ which are classed as "never events" but continue to occur. ${ }^{6}$ Laterality errors are not restricted to the operating room, however. ${ }^{7}$ A further complexity of right-left discrimination in clinical practice is that, when facing a patient or client, your right side is opposite their left side, which means mental rotation is also required. It is possible that errors of right-left discrimination occur more commonly in health care than is reported.

Adverse events involving patients are often multifactorial in origin; a series of events and latent conditions in a complex system become

\section{- Ker POINTS}

- Innately, some individuals are challenged with correctly discriminating right from left.

- Adverse patient events are often multifactorial in origin and include human-factor issues.

- Further research is required to discover how inherent human vulnerabilities, such as difficulty with right-left discrimination, contribute to clinical errors and whether remediation via educational interventions might reduce error rates.

unfortunately aligned. Although it is uncommon for any single action to be solely linked to an adverse event, human error is one of many identified root causes. ${ }^{8}$ To date, the literature has largely overlooked whether and to what extent an individual's innate inability to correctly discriminate right from left contributes to laterality errors causing patient harm.

Early on in medical curricula, we emphasize correct anatomic spatial orientation: anterior from posterior, superior from inferior - why not right from left? Given that not everyone has equal ability to discriminate between right and left, ${ }^{1,2}$ perhaps right-left discrimination should be tested as trainees progress to become health care professionals, particularly in specialties in which there is greater likelihood for human actions to cause patient harm (e.g., surgery). Such testing could facilitate greater awareness of one's potential vulnerabilities and reinforce the need to be mindful when making right-left decisions, especially for risky procedures. However, is mere heightened vigilance a sustainable and infallible strategy? Likely not, given that evidence now shows that common clinical distractions (e.g., verbal interruptions and ambient noise) can substantially affect individuals' ability to correctly discriminate right from left and the consistency with which they employ personal adaptive strategies. ${ }^{9}$

At a curricular level, simulation-based education may be used to give hands-on experience with situations in which laterality errors (and other human-factor issues) typically arise, but without any risk of patient harm. Training would need to extend beyond simply addressing competencies in the technical components of procedural skills. A large UK-based study, for instance, found that junior doctors largely felt prepared for carrying out procedures but underprepared for the many human-factor, environmental and interpersonal challenges they confronted in their busy working environments. ${ }^{10}$

Health care organizations have learned, and will continue to learn, error-management strategies from the aviation industry, such as crew resource management. At a systems level, anticipating what can go wrong and having a remedial action plan goes some way toward reducing the potential for patient harm. Although initiatives 
such as the World Health Organization Surgical Safety Checklist have made a substantial impact on the prevention of "never events," such as wrong-site surgery, ${ }^{11}$ it may be wise to further extend such checklist strategies beyond the operating room to the ward procedure or clinic setting.

Training to mitigate the effects of right-left discrimination impairment would need to integrate the educational and clinical environments by, for example, producing simulated ward-based training opportunities that include explicit (and implicit) physical, sensory, psychologic and emotional cues to represent the complexities experienced by practising health professionals. Learners need to experience key skills such as dealing with uncertainty, complexity and distraction in clinical scenarios. ${ }^{12}$ For example, in a simulated ward-based learning exercise, a junior doctor may be tasked to produce a request for a left-leg venogram but be distracted by intentional interruptions such as being notified by a nurse regarding a clinical task in another area of the ward. Providing distraction-free zones for making important decisions (akin to the distraction-free zones for prescribing in some intensive care units) may be useful, particularly for those who need to overcome the limitations of difficulty with right-left discrimination. Research into such educational strategies is needed to guide how training can best prepare health care professionals and minimize patient error.

Clinical skills are contextualized activities they never occur in isolation. Clinical humanfactor theories consider the enmeshed interaction between the behaviours of health care professionals and the many situational factors of a complex health care system. From a human-factors perspective, difficulty in right-left discrimination can be considered one cog in the machine in terms of opportunities for error. Health care systems have made substantial progress in reducing wrong-side errors, ${ }^{11}$ but more work needs to be done. Reducing laterality errors requires a greater understanding of the influence of inherent human behaviours (both our capabilities and vulnerabilities) and our dynamic, nonlinear interactions with more established "faults" contributing to error, such as social processes, systems and organizations. To optimize clinical performance and reduce adverse events, human-factor theories need to be nested in the challenging environments of modern-day health care provision. Because difficulty with right-left discrimination is relatively common, it is important to research both its unique impact as a "human factor" on clinical error and its tractability to remediating intervention.

\section{References}

1. Ofte S, Hughdahl K. Right-left discrimination in male and female, young and old subjects. J Clin Exp Neuropsychol 2002; 24:82-92.

2. Gormley GJ, Dempster M, Best R. Right-left discrimination among medical students: questionnaire and psychometric study. BMJ 2008;337:1474-5.

3. Wolf SM. Difficulties in right-left discrimination in a normal population. Arch Neurol 1973;29:128-129.

4. Corballis MC, Badzakova-Trajkov G, Häberling IS. Right hand, left brain: genetic and evolutionary bases of cerebral asymmetries for language and manual action. Cogn Sci 2012;3:1-17.

5. Speak up: the universal protocol for preventing wrong site, wrong procedure, and wrong person surgery: guidance for health care professionals. Oakbrook Terrace (IL): The Joint Commission; 2011. Available: www.jointcommission.org/assets/1/18/ UP_Poster.pdf (accessed 2015 Aug. 5).

6. Provisional publication of never events reported as occurring between 1 April and 19 May 2015. London (UK): NHS England. Available: www.england.nhs.uk/wp-content/uploads/2015/06/ prov-ne-data-apr-may-15.pdf (accessed 2015 Oct. 23).

7. Miller KE, Mims M, Paull DE, et al. Wrong-side thoracentesis: lessons learned from root cause analysis. JAMA Surg 2014;149: 774-9.

8. Seiden SC, Barach P. Wrong-side/wrong-site, wrong-procedure, and wrong-patient adverse events: Are they preventable? Arch Surg 2006;141:931-9.

9. McKinley J, Demspter M, Gormley GJ. 'Sorry, I meant the patient's left side': impact of distraction on left-right discrimination. Med Educ 2015;49:427-35.

10. Monrouxe LV, Bullock A, Cole J, et al. How prepared are UK medical graduates for practice? Final report from a programme of research commissioned by the General Medical Council. United Kingdom: General Medical Council; 2014. Available: www.gmc-uk.org/How_Prepared_are_UK_Medical_Graduates _for_Practice_SUBMITTED_Revised_140614.pdf_58034815. pdf (accessed 2015 Aug. 5).

11. WHO surgical safety checklist. Geneva: World Health Organization; 2009. Available: www.nrls.npsa.nhs.uk/resources/clinical -specialty/surgery/?entryid45=59860 (accessed 2015 Aug. 5).

12. Fenwick T, Dahlgren MA. Towards socio-material approaches in simulation-based education: lessons from complexity theory. Med Educ 2015;9:359-67.

Affiliations: Centre for Medical Education (Gormley), Queen's University, Belfast, Northern Ireland; Department of Medicine and The Wilson Centre (Brydges), University of Toronto and University Health Network, Toronto, Ont.

Contributors: Both authors contributed to the conception of this article. Gerard Gormley drafted the article, which both authors revised. Both authors gave final approval of the version to be published and agreed to act as guarantors of the work. 